\title{
Self-Monitoring as a Personality Variable in Tinto's Theory of Integration
}

\author{
Wade Smith, PhD \\ Southeastern Louisiana University \\ Sean Forbes, PhD \\ Auburn University \\ Rebecca Robichaux-Davis \\ Mississippi State University \\ Anthony J. Guarino \\ Fulbright Institute
}

\begin{abstract}
One weakness of Tinto's model is its inability to identify early dropouts, which may be due to the theory's inattention to personality traits. Self-monitoring may be an important trait related to dropout. This study hypothesized low self-monitors, compared to high self-monitors would be more likely to (1) have higher initial commitment levels, (2) achieve higher academic integration, (3) accomplish greater social integration, and (4) persist in college. Path analysis confirmed all hypotheses. Self-Monitoring was demonstrated to be an important personal characteristic in Tinto's Theory. Application of these findings are discussed.
\end{abstract}

Keywords: college, retention, academic, social, integration

\section{SELF-MONITORING AS A PERSONALITY VARIABLE IN TINTO'S THEORY OF INTEGRATION In the research literature on student attrition, Tinto's Model of Integration appears to be the most widely cited [1]. Tinto generated an explanatory, predictive model of voluntary withdrawal that has at its core the commitment level of the student. This commitment level then influences two key areas of student persistence: academic integration and social integration with the college. This longitudinal model postulates that persistence is the result of a "fit" between the individual and the institution. A number of quantitative studies have supported the validity of institutional integration to account for attrition, e.g., those performed by Getzlaf, Sedlacek, Kearney, and Blackwell [2], Munro, [3], Napoli and Wortman, [4], and Stinson and Walter [5].}

However, studies by Webb [6] and Halpin [7] reviewed the Tinto model and concluded that it was inadequate if the intent is to identify potential dropouts as early as possible. This lack of early identification of potential dropouts might be explained by the fact that Tinto ignores personality traits in his theory. In fact, he asserts that there is no personality-type inclined towards attrition. Not surprisingly, personality traits have been ignored involving Tinto's Model.

One personality trait hypothesized to identify students likely to commit and ultimately persist is self-monitoring, proposed by Snyder [8]. The self-monitoring construct distinguishes 
between those who are especially attuned to the role expectations of other people (high selfmonitors) and those who insist on being themselves despite social expectations (low selfmonitors). High self-monitors have been characterized as pragmatic and utilitarian in their view of life, whereas low self-monitors have been described as committed and principled. High self-monitors strive to maintain flexibility and make little emotional investment. Low selfmonitors, by contrast, tend to invest emotionally. High self-monitors are likely to be less attached than low self-monitors to the network of friends and colleagues and to be more flexible about the possibility of forming new relationships elsewhere. Jenkins [9] reported that high self-monitors are more likely than low self-monitors to express intentions to leave a current job. They are likely to feel relatively unconstrained about opportunity wherever it may be found, whereas low self-monitors are likely to be more committed to current commitments.

The hypotheses of this study are: Compared to high self-monitors, low self-monitors will be more likely to (1) enter with higher commitment levels, (2) achieve higher academic integration, (3) accomplish greater social integration, and (4) persist.

The present article represents probably the first investigation to determine whether Snyder's Self-Monitoring Scale could be utilized in Tinto's Model.

\section{Participants}

\section{METHOD}

The subjects were 262 community college students enrolled in an introductory psychology class. The student population was ethnically diverse: 20\% White; 20\% Mid-Eastern; 20\% Asian; 10\% Latino; 5\% Black; and 25\% listing themselves as Other. Slightly more than half (51\%) was female. The age range was 17-53 years with most students falling into the 18-25 age range.

\section{Materials}

Self-Monitoring was measured by the 18-item true-false Self-Monitoring Scale (Snyder, 1984) with items measuring high self-monitoring coded as 1 . The sample was split so that those with scores of 11 or higher were classified as high self-monitors; those with scores of 10 or less, as low self-monitors.

Integration levels were assessed by using a 34-item instrument developed by Pascarella and Terenzini [10] to assess students' experiences with the social and academic systems of the college.

\section{Procedure}

During the second week of the semester, students completed the Self-Monitoring Scale. Integration levels were assessed with the instrument developed by Pascarella and Terenzini [10] during the last week of the semester.

\section{RESULTS}

Path analysis was employed to evaluate the causal model in this study. To assess the significance of the relationships stated in the hypotheses, logistic and simultaneous regression equations were implemented. A comparison of the path coefficients revealed the relative importance that the exogenous and endogenous variables had on the dependent variable in the theoretical models.

Institutional Goals and Commitments. The first equation in the structural model included the effects of the four exogenous variables (gender, self-monitoring, HSGPA, and minority status) 
on institutional goals and commitments. High institutional commitment is associated with low self-monitoring, $\mathrm{t}(270)=-6.39, \mathrm{p}<.05)$

Academic Integration. This structural equation assessed the effects of the four exogenous variables (gender, self-monitoring, HSGPA, and minority status) and one endogenous variables (institutional commitments) on academic integration. Low self-monitors, $\mathrm{t}(203)=-2.68, \mathrm{p}<$ .05 , had a significant direct effect on academic integration.

Social Integration. This structural equation assessed the effects of the four exogenous variables (gender, self-monitoring, HSGPA, and minority status) and one endogenous variable (institutional commitments) on the dependent variable, social integration. A comparison of the standardized coefficients revealed that low self-monitoring, $\mathrm{t}(203)=-5.14 ; \mathrm{p}<.05$, had a significant direct effect on social integration.

Persistence. A standard logistic regression was utilized to identify the significant paths for the last structural equation. The dependent variable persistence was regressed on four exogenous variables (gender, self-monitoring, HSGPA, and minority status) and three endogenous variables (institutional commitments, academic integration, and social integration). Low selfmonitors, $\operatorname{Wald}(1)=4.73, \mathrm{p}<.05$, were significantly more likely to persist.

\section{DISCUSSION}

The results of this study confirmed all four hypotheses that low self-monitors would be more likely than high self-monitors to: (1) enter with higher commitment levels, (2) achieve higher academic integration, (3) accomplish greater social integration, and (4) persist. The weakness of Tinto's Model in its inability to predict potential dropouts early (Webb, 1988) is addressed in this study. These findings could be applied to identify potential "at-risk" students early and provide these students with the necessary counseling to insure successful completion of their academic pursuits.

\section{References}

Cleveland-Innes, M. (1994) Adult Student Drop-Out at Post-Secondary Institutions. In: Review of Higher Education, 17:4, pp.423-45.

Getzlaf, S. B., Sedlacek, G. M., Kearney, K. A., Blackwell, J. M., (1984). Two Types of Voluntary Undergraduate Attrition: Application of Tinto's Model. In: Research in Higher Education, 20:3, pp 257-268.

Munro, B. M., (1981). Dropouts from Higher Education: Path Analysis from a National Sample. 18:2, pp.157-171.

Napoli, A.R. \& Wortman, P.M., (1998). Psychosocial Factors Related to Retention and Early Departure of Two-Year Community College Students. In: Research in Higher Education, 39:4, pp.419-455.

Stinson, M., \& Walter, G. (1992). Persistence in College. In S. G. Foster \& G. G. Walter (Eds.), Deaf students in postsecondary education (pp. 43-64). New York, NY: Routledge.

Webb, M. W. (1988). Freshman Year Retention at Three Campuses of a Large Urban Community College District: 1983-1986. In: Community/Junior College Quarterly, 12, pp.213-242.

Halpin, R. L., (1990). An Application of the Tinto Model to the Analysis of Freshman Persistence in a Community College. In: Community College Review, 17:4, pp.22-32.

Snyder, M. (1974). Self-Monitoring of Expressive Behavior. In: Journal of Personality and Social Psychology, 30(4), pp.526-537.

Jenkins, M. J., (1993). Self-monitoring and turnover: The impact of personality on intent to leave. In: Journal of Organizational Behavior, 14:1, pp.83-91.

Pascarella, E. T., Terenzini, P. T., (1980). Predicting Freshman Persistence and Voluntary Dropout Decisions from a Theoretical Model. In: Journal of Higher Education, 51:1, pp.60-75. 